\title{
The Role of Digitalization in the Target Scenario of Russian Economic Development
}

\author{
D. R. Belousov ${ }^{a}$, K. V. Mikhailenko ${ }^{a}$, E. M. Sabel'nikova ${ }^{a,}$ *, and O. G. Solntsev ${ }^{a}$ \\ ${ }^{a}$ Institute of Economic Forecasting, Russian Academy of Sciences, Moscow, 117418 Russia \\ *e-mail: esabelnikova@forecast.ru \\ Received December 21, 2020; revised January 12, 2021; accepted February 10, 2021
}

\begin{abstract}
The article considers the contribution of the ICT sector to the medium- and long-term development of the Russian economy. The target scenario of Russian economic development and the conditions necessary for its implementation are analyzed. The necessity of completing the ICT Ecosystem to full cycle is substantiated. The strategies of fostering "national champions" are analyzed, and a target strategy is defined.
\end{abstract}

Keywords: economic growth, information and communication technologies (ICT), digitalization, forecasting, scenarios, markets, national champions, ecosystem

DOI: $10.1134 / \mathrm{S} 1075700721040055$

Trends and factors that define scenarios of global and russian economic development. The last year and a half has been marked by profound changes in the global economy.

On the one hand, as the global economy begins to recover from the crisis, global competition significantly increases, both in general and specifically in markets for high-tech products (such as IT platforms or vaccines), which were previously mainly controlled by a group of the most developed countries. However, security requirements (availability of our own IT solutions in the field of communication, a set of competencies in the field of biomedical technologies, etc.) and rising costs of factors of production (for example, labor in China) will most likely inhibit global growth in the long term. In this context, bringing the Russian economy up to a steady annual growth rate of $3-3.5 \%$ will be much more difficult under these new conditions than it was, for example, 5-7 years ago.

On the other hand, the role of global IT companies (Big Tech) that supply platform solutions for business, information, and finance has dramatically increased. In this context, our country needs to focus on not just accelerated economic development, but particularly on rapid development of the new "core" of the economy - the ICT sector, as well as on intensive organizational construction aimed at fostering domestic IT companies of a global scale.

The major midterm trends that are currently shaping the conditions of socioeconomic development in the long-term are the following.

1. Gradual recovery of the global economy from the coronavirus crisis, return to the growth trajectory. It should be noted that the situation on the global mar- ket remains extremely unstable. As the "second" and "third" coronavirus waves develop, the risks of a crisis in the corporate debt market and/or defaults of individual countries, as well as "bubble bursts" in financial asset markets, remain. At the beginning of the COVID-19 pandemic, the global economy was in a state of cyclical overheating: many international organizations, including the World Bank, had brought attention to indicators of excessive of debt load growth and overheating. It is highly probable that the current crisis will trigger at least a cyclical "clearing" of debts and overconsumption, at most structural adjustments. The probability of the former increases dramatically if the pandemic remains a problem for a long time, and the latter if the US-China conflict becomes more acute.

2. Moderate expansion of demand for hydrocarbons due to environmental constraints, technological shifts, or a (possible in some scenarios) slowdown of the global economy caused by a structural crisis.

Oil prices will be primarily influenced by oversupply in the oil market (previously partially offset by the "withdrawal" of Venezuelan oil from the market and the additional reduction in Saudi oil exports in the fourth quarter of 2020). It should be emphasized that this factor affected the economy even before the crisis reduction of fuel demand caused by the collapse of air travel.

3 . The increasing importance of the factor of economic (US/China) and geopolitical conflicts, the transformation of the factors of geo-economic and geopolitical conflicts into a permanent risk factor for the Russian and global economies.

4. The increasing importance of technological (and environmental) factors for shaping economic dynam- 
ics, especially in certain most sensitive sectors (oil, coal, trade, etc.).

The situation at the start of the forecast period was characterized by the following distinctive features that determine the specifics of future development and especially the risks of a global financial and/or cyclical crisis and, accordingly, a protracted crisis in Russia [1]:

- Large-scale losses of the Russian economy as a whole $^{1}$ and a number of its industries, which creates rather difficult starting conditions for overcoming medium-term aspects of the crisis (naturally, the unused production potential reserves create an opportunity for a "quick rebound," but only in certain conditions).

-A combination of prolonged stagnation in the Russian economy with weak signs of a beginning of a new recovery against the background of final stages of its adaptation to new working conditions (sanctions, the increased VAT and the increased retirement age); final preparations for the implementation of the National projects system.

-Limited opportunities for development at the expense of natural rent, which creates the need for debt financing for development.

-The need to simultaneously address the challenges of overcoming the crisis and of building the potential for future development (national projects).

Another fact of probable importance is the emergence of "digital giants," which in the conditions of rapid digitalization of society control key services and infrastructure of the global digital economy. This, on the one hand, accelerates and to a certain extent reduces the cost of the digital transformation of business and social processes, but on the other hand, monopolizes markets, prevents competition, and places the activities of enterprises and organizations around the world under the control of these digital giants. Such digital national champions have properties that enable them to consistently maintain and improve their market positions and manage the creation and development of huge market segments. They have the following advantages:

- They provide growth and development points for new technologies, buy technological developments around the world, and seek to capture unformed markets.

- They define market standards, create and promote new business models; the market and economic

\footnotetext{
${ }^{1}$ Cumulative losses of the Russian economy from the COVID-19 pandemic are estimated at $3.5 \%(3.4-3.8 \%)$ of GDP growth. This estimation is based on the fact that as a result of all related events (including the decrease in oil prices), GDP will decrease by $4.6 \%(4.5-4.8 \%)$ instead of the expected growth of $1.3 \%$ $(1.2-1.5 \%)$. This assessment includes not only the immediate effect of the quarantine within the country, but also, for example, the drop in the volume of metal exports (caused by the crisis in the global investment sphere, the suspension of civil aircraft production) and oil exports (caused by the transportation crisis). The impact of the decrease in oil prices of $2.4 \%(2.3-2.6 \%)$ has been eliminated.
}

strength of such national digital champions enables them to structure not only national, but also foreign business, and in some cases also information flows and forms of public activity.

-They attract significant capital: almost all companies in the top 10 of the Nasdaq index by capitalization have their own global platforms and ecosystems, and some of the companies on that list use their ecosystems to manage global ICT infrastructures.

Currently, no Russian corporations are able to manage global digital platforms and influence the global infrastructure of the digital economy to the extent that American, European, and Chinese corporations do.

The total potential of Russia's economic growth is currently about $2-2.5 \%$ per year. However, that is not enough to solve the long-term problems. Besides, Russia loses about $1-1.5$ pp of GDP per year due to the negative influence of medium-term factors (lagging in total factor productivity), which prevents effective use of production and labor potentials. Thus, solving structural problems in the medium term may increase growth to about 3-3.5\% [1].

These parameters are achievable if the country's socioeconomic and scientific-technological development follows the target scenario (Table 1).

Other scenarios mean either adapting to the continuous turbulence of global markets (the crisis scenario) or avoiding risks and correspondingly maintaining low rates of development due to the lack of structural maneuvering from the traditional (energy and resource-based) to the new economy (traditional markets). Separate consideration should be given to the possibility of failure of economic modernization due to business distrust of state efforts to digitalize the economy (the state ecosystem scenario), in which technologically mature sectors of the economy respond to the stimulative state policy and develop successfully, but new ICT-based industries develop poorly.

Only the target scenario of socioeconomic development of Russia and development of the ICT sector, its results and prerequisites, is considered further.

Overview of the target scenario. The core idea of the target scenario is to accelerate the development of the economy and society at the cost of accepting additional risks in a controlled manner. Its logic and main characteristics generally correspond to the parameters specified in the strategic documents of medium- and long-term development, in particular, those laid down in the national development goals for the period up to $2030^{2}$.

External conditions in this scenario are based on the assumption that the quarantine shock to the global economy does not become cyclical, much less struc-

\footnotetext{
2 Decree of the President of the Russian Federation of July 21, 2020 No. 474 On the National Development Goals of the Russian Federation for the Period up to 2030.
} 
Table 1. Scenario matrix of the development of the global economy, the Russian economy, and the Russian ICT sector

\begin{tabular}{|c|c|c|c|c|}
\hline $\begin{array}{c}\text { Global economy } \\
\text { development scenario }\end{array}$ & \multicolumn{3}{|c|}{$\begin{array}{c}\text { Basic scenario: } \\
\text { economic cycle with moderately fast growth rates based on } \\
\text { technologies (ICT, eco-, bio-); } \\
\text { slowly increasing oil prices, stagnation of oil markets; } \\
\text { accelerated growth of machinery and equipment markets; } \\
\text { a lot of capital on the markets; diffusion of technologies from more } \\
\text { developed countries with cheap factors of production }\end{array}$} & $\begin{array}{c}\text { Crisis scenario: } \\
\text { structural crisis - a } \\
\text { series of debt crises and } \\
\text { recessions on } \\
\text { individual markets; } \\
\text { China slowing down; } \\
\text { low prices on oil, gas, } \\
\text { and metals }\end{array}$ \\
\hline $\begin{array}{l}\text { Russia's socio-eco- } \\
\text { nomic development } \\
\text { scenario }\end{array}$ & \multicolumn{2}{|c|}{$\begin{array}{c}\text { Target scenario: } \\
\text { the state stimulates technological moderniza- } \\
\text { tion; } \\
\text { high policy efficiency, fast transmission of } \\
\text { efforts into economic growth }\end{array}$} & $\begin{array}{c}\text { Traditional markets: } \\
\text { policy of low risks and } \\
\text { stabilization }\end{array}$ & $\begin{array}{c}\text { Crisis scenario: } \\
\text { adaptation to continu- } \\
\text { ous turbulence }\end{array}$ \\
\hline $\begin{array}{c}\text { ICT development sce- } \\
\text { nario }\end{array}$ & $\begin{array}{l}\text { Target scenario: } \\
\text { active state efforts - } \\
\text { business develops } \\
\text { intensively, synergy is } \\
\text { achieved. Rapid } \\
\text { buildup of ICT Ecosys- } \\
\text { tem capacities etc. }\end{array}$ & \begin{tabular}{|} 
"State ecosystem": \\
active state efforts of \\
developing the ICT \\
Ecosystem are met with \\
"business distrust"*
\end{tabular} & $\begin{array}{l}\text { Narrow focus: } \\
\text { digital modernization } \\
\text { of a relatively small } \\
\text { group of traditional } \\
\quad \text { exporters }\end{array}$ & Not considered \\
\hline
\end{tabular}

* The phrase "business distrust" here means that business is neutral to measures of stimulative state policy in the field of ICT and does not adapt or poorly adapts its own development strategies to these measures.

tural. There is no financial crisis in the corporate and/or public sectors. Efforts to stimulate economies will limit the number of national economic crises throughout the recession, and the financial "contagion" will be suppressed by measures taken by central banks.

The global economy is expected to quickly rebound after the 2020 crisis downturn (to $5.5-5.7 \%$ growth in 2021) and develop quite rapidly (about $3 \%$ per year), slowing down to about $2 \%$ per year during the cyclical crisis period (2025). Thus, in terms of trajectory the current crisis can be described as a "V-" (rapid fallimmediate rapid rebound) or a "short U-" crisis (rapid fall-short depression phase-rapid rise).

In the new conditions, the most important factor that determines the potential for economic development will be the competition of global ICT platforms. The barriers to entering the platform market are already quite high, but the potential of that market is also enormous.

In Russia this scenario assumes an active state policy of stimulating modernization of the economy, which includes supporting the investment process (including public investment in infrastructure, support for long investment contracts and investments in new sectors of the economy, digitalization of the economy, export of new products, etc.).

As a result, this scenario maximizes the realization of the "nonenergy" growth potential and would enable the country to achieve fairly high rates of economic growth for a rather long time. In this regard, this scenario of maximum possible realization of both pro- duction and export potential (particularly of high-tech products, including ICT products) is the only one that can be considered the target scenario. Under this scenario, Russian GDP dynamics will reach a rate of about $3 \%$ per year by 2028 (Fig. 1), which roughly corresponds to global dynamics, and thus one of the main national development goals is achieved.

The ICT sector in the target scenario. Implementation of the target scenario for the economy as a whole is impossible without successful development of the ICT sector. Its contribution to overall economic dynamics is assessed based on an improved ${ }^{3}$ quantitative model of the ICT Ecosystem, developed in 2017, which incorporates the relationships between the main participants of the Ecosystem and the influence of external factors on its functioning. A detailed description of the Ecosystem model can be found in [5, 6].

The target scenario assumes that active efforts are being made to develop both the potential of the ICT Ecosystem (investment in education, capitalization of development institutions, etc.) and the initial state demand for its products. In addition, it is assumed that

\footnotetext{
${ }^{3}$ In particular, the model includes a block for assessing the impact of the development of applied R\&D in the field of ICT. When selecting links for modeling, several options for the development of national innovation systems (NIS) were compared based on the experience of previous studies [2,3]. The nature of the impact of the development of applied R\&D in the field of ICT on the dynamics of the indicators of the ICT sector was assumed to be similar to the corresponding conceptual scheme for science as a whole [4].
} 


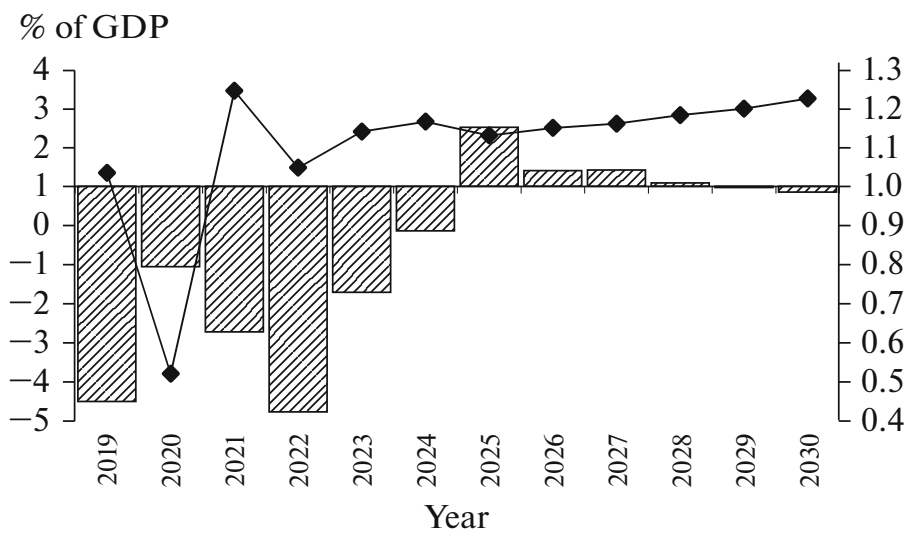

Fig. 1. GPD dynamics (- -) and growth elasticity of Russia’s GDP by global economic growth (: $)$ (right scale).

business positively reacts to public policy measures aimed at achieving national goals and adapts its own development strategies in accordance with these measures. Correspondingly, a high level of private demand for ICT products, active exports of ICT products, and high investment multiplication rates and returns on them are expected.

A high level of activity in the field of demand for digital technologies from both the ICT sector itself and traditional companies is observed.

The target scenario for the Ecosystem is based on the combination of active state policy of stimulating the economy and accelerated development of the ICT sector. The process of implementing the necessary set of measures included in the scenario should involve creating a system of effective interaction between development institutions, state-owned companies, traditional sectors of the Russian economy, and hightech SMEs in the context of growing demand for IT products.

The target scenario has the following prerequisites:

1. Large-scale state financing of ICT Ecosystem development, both directly through demand for digital technologies and indirectly by supporting the capitalization of development institutions, both specialized and general, concentrated around VEB.RF and the RDIF $^{4}$.

2. Rapid human resource development in the ICT Ecosystem. The national program "Digital Economy of the Russian Federation" assumes a deliberate increase in the training of ICT specialists, which implies a sharp jump in public spending on human resource development in the period up to $2025^{5}, 15-$

\footnotetext{
${ }^{4}$ State development corporation VEB.RF, Russian Direct Investment Fund.

${ }^{5}$ The forecast for training ICT specialists incorporated the planned increase in the target university admission figures for IT specialties from 50 thousand in 2019 to 120 thousand in 2024, as specified in Federal project "Personnel for digital economy" of the national program "Digital economy of the Russian Federation."
}

$20 \%$ per year (in real terms). Later the dynamics of spending on ICT training decreases to an inertial growth rate of about $3 \%$ (Fig. 2).

As a result, the number of employees in the sector will almost double compared to the current level from 1.5 to 3 million people.

3. Rapid technological development in the ICT sector. This scenario assumes acceleration of technological development (globally and in Russia) and rapid expansion of ICT throughout the Russian economy and society. In terms of technological development in the field of ICT, Russia will approach the current level of developed countries ${ }^{6}$.

As a result, under this scenario the trend of intensive expansion of the added value of the ICT sector that has been observed in recent years is expected to continue. According to the forecast, the added value produced by ICT sector enterprises in real terms will by 2030 increase 2.5 -fold compared to the 2020 level (Fig. 3).

In the structure of demand for ICT products, the contribution of traditional companies that are in the process of digitalization is expected to increase rapidly (from 1.2 pp of composite demand growth in 2018 to $4.7 \mathrm{pp}$ in 2030) (Fig. 4). The contribution of the already digitalized trade and the financial sector is likely to remain at its current level.

The volume of exports in dollar terms will by 2030 increase 2.7-fold compared to the 2020 level. The share of ICT goods and services in the structure of exports will reach $4.6 \%$, and in the structure of imports $17.1 \%$ (Fig. 5).

\footnotetext{
${ }^{6}$ In particular, by the end of the forecast period the ICT development index will be about 8.4. The ICT development index is a composite index that has been calculated since 2009 by the International Telecommunication Union and characterizes the availability and use of ICTs, as well as practical ICT skills of the population [7]. According to the latest available data (for 2017), Russia ranked 45th among 176 countries of the world with an index value of 7.07. The value of 8.4 corresponded to Japan, Sweden, and Germany (places 10-12 in the rating).
} 


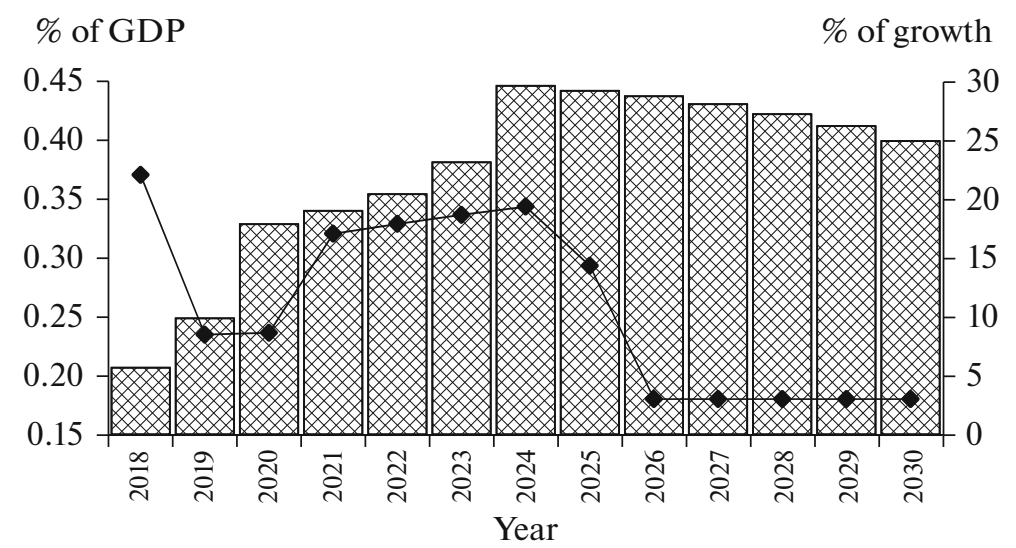

Fig. 2. Share of state spending on ICT (网) and dynamics of state spending on higher and secondary ICT education (-৮-) (right scale).

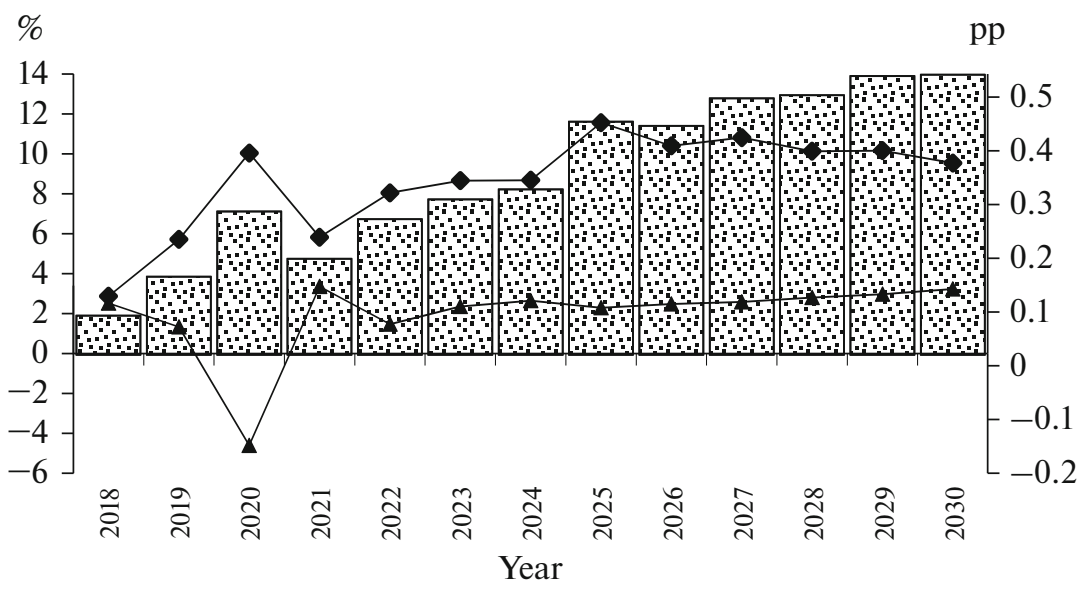

Fig. 3. Dynamics of added value in ICT $(-\bullet-)$ and Russia's GDP $(-\boldsymbol{\Delta}-)$ and ICT contribution to GDP growth (ㅂ.ं) (right scale).

“Fostering” national champions. It should be noted that the state is actively making efforts to create resources for stimulating development of the ICT sector. Such efforts include both the "push" approach to the sector's development (creating resources of various kinds, infrastructure, ICT training, software, etc.) and the "pull" approach (stimulating demand for ICT products, both from government agencies and partly from corporations and the population). However, the effectiveness of these actions is currently insufficient.

The new economic structure that has developed in the world, characterized by BigTech companies occupying key positions in terms of both organizing business infrastructure and of attracting capital, would not permit a full-scale breakthrough ${ }^{7}$ without structures of similar capacity under national control.

\footnotetext{
${ }^{7}$ Let us emphasize that this concerns exclusively the target scenario of socioeconomic and scientific and technological development. The adaptation scenario has neither resources nor sufficiently large-scale tasks for this; in the traditional markets scenario, ICTs are in a subordinate position in relation to traditional raw resource structures.
}

The current lack of global technological champions leads to a systemic problem that hinders the country's economic development, complicates and increases the cost of developing the digital economy, and creates systemic risks, such as the following:

-High vulnerability of the technological ICT infrastructure, difficulty of resisting the pressure of sanctions from countries that own most of the infrastructure.

-Insufficient internal "drivers" for the scientific and technical complex and the innovation and entrepreneurial ecosystems.

-Losses in the battle for ICT standardization that cause Russian developments to be excluded from global value chains, which means losing export markets.

-Slow pace of creation of a global technological pole in the country, which would provide an alternative set of digital platforms and solutions for countries that need alternatives to American, European, and Chinese platforms. 


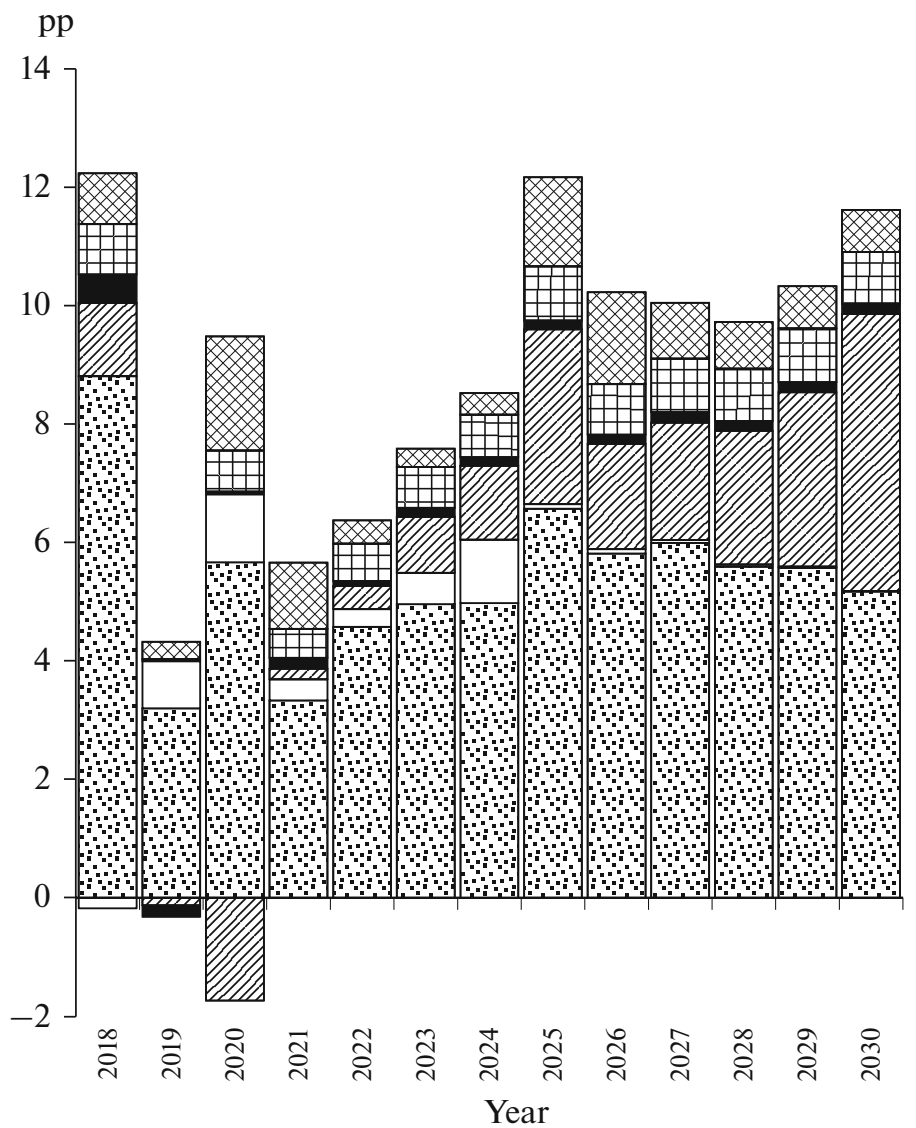

Fig. 4. Contributions of individual components to growth of internal demand for ICT products, at 2016 prices: population; $\square$ state; $\square$ traditional companies; $\square$ trade; 田 financial sector; $\otimes$ exports.

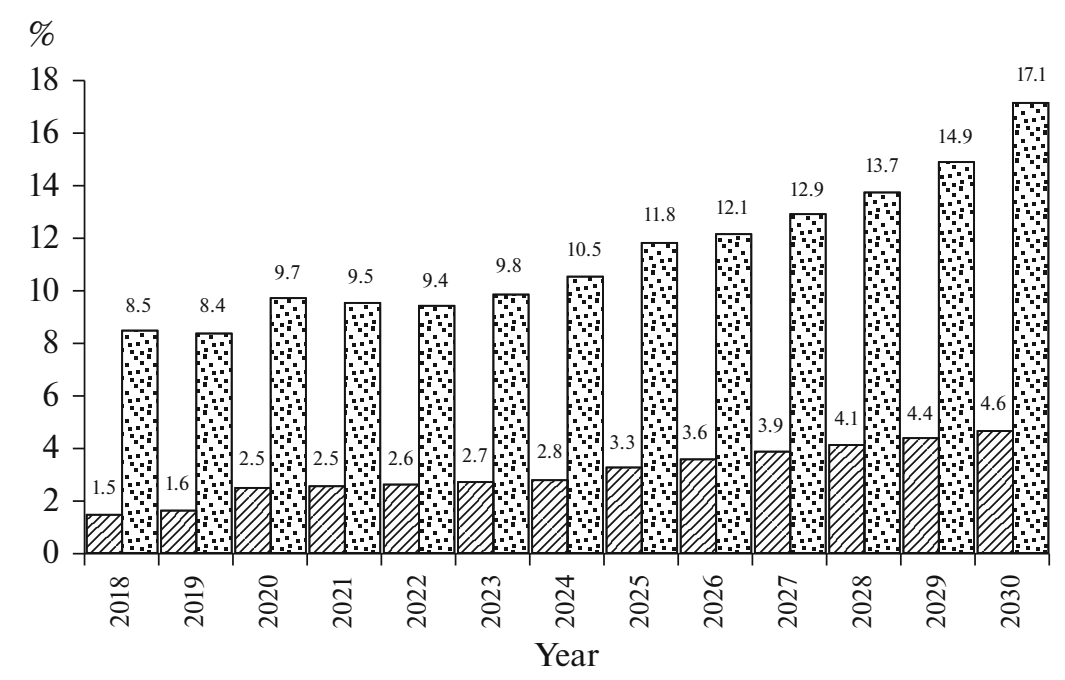

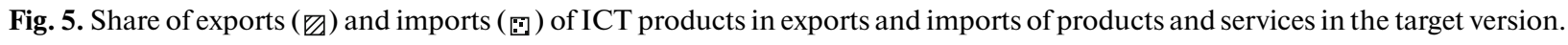

Thus, in addition to investment and human resource development, the target scenario requires a qualitative change in the Ecosystem, specifically, completing it to full cycle. Currently, Russia effectively has no "upper layer" of IT companies, that is, global IT champions. 
Table 2. Strategies for fostering national champions

\begin{tabular}{l|l|l|l}
\hline \multicolumn{1}{c|}{ Development model } & \multicolumn{2}{|c|}{ Public-private partnership } & State ecosystem \\
\hline Financing model & $\begin{array}{l}\text { Financing through major industry } \\
\text { players and financial institutions }\end{array}$ & $\begin{array}{l}\text { Financing through attracting } \\
\text { capital of the financial market }\end{array}$ & $\begin{array}{l}\text { State financing, state devel- } \\
\text { opment institutions }\end{array}$ \\
\hline
\end{tabular}

Fostering national champions is becoming one of the key objectives of the development of the Russian ICT sector. Without solving that problem, achieving the relatively high rates of economic growth and goals set in national projects would be extremely difficult.

Strategies of fostering national champions are generally determined by two groups of factors (Table 2 ).

First are models for long-term development of the ICT Ecosystem. The main ones are the following.

1. The public-private partnership model. This model assumes that the state implements a policy of active support for economic growth and technological modernization, i.e., an effective combined policy for the development of both ICT resources (educational, financial, etc.) and demand for the sector's products.

Crucially, in this scenario ICT development is based on a focus on the interests of private business, in terms of both demand for products and involvement of private capital in the financing of IT projects. The target scenario for the Ecosystem is based on a combination of an active stimulative state policy and accelerated development of the ICT sector. The process of implementing the necessary set of measures set in the target scenario should involve creating a system of effective interaction between development institutions, state-owned companies, traditional sectors of the Russian economy, and high-tech SMEs.

2. The state ecosystem model. This model assumes a policy of active state support at the same scale as in the target scenario. However, this scenario involves high risks of weak business support for these initiatives. Thus, the ecosystem remains "state-adjacent," reliant on state orders for specific ICT developments, the education system, etc.

Secondly, within the business-oriented model of IT ecosystem development, the key issue is the "loadbearing financial resource," which is a financing characteristic used for the development of national champions.

Generally, two approaches are possible.

First approach. Relying on the funds of strategic investors (financial companies, real sector organizations) with specific competencies in industry markets and interests in the field of ICT. Such financing can take the form of both long-term lending and direct investment in promising IT companies.

The advantages of this approach are, on the one hand, the focus on the specific demand of Russian companies (backed upfront by funding and expert support), on the other, the ability to use the synergy of competencies of various groups of players interested in
ICT development (specifically, development institutions, industry corporations-consumers, and supported IT companies).

The systemic disadvantages of this construction are the following:

-Limited financial resources of partner companies, both the real sector and financial organizations (this can become especially significant in the late stages of fostering potential champion companies).

-The presence (with consideration to the peculiarities of the domestic corporate culture) of a conflict of interest among corporate partners: the logic of the process of fostering global champions contradicts the goal of maximum "economic security" and absorption of promising partners with unique, critical competencies that is typical for a number of Russian companies.

-Cultural and institutional barriers to expansion directly onto the global market from the Russian market.

Second approach. Relying on the resources of the open global financial market (through IPOs (initial public offerings) or other ways of attracting free capital). The advantages are the possibility of relatively rapid scaling of financial resources for the development of national champions and transparency of the market-assessment method for external players.

The disadvantages of the approach are the following:

-The risk of losing national control over the assets, which directly contradicts the goal of fostering digital champions as a tool for strengthening sovereignty.

-Increased susceptibility to instability due to global market risks.

Obviously, none of the options in their pure forms are sufficient to solve the problem of developing existing IT companies to the scale of globally significant IT market players. The state-centric policy of fostering champions is probably ineffective; most likely, the companies would end up locked in the limited scale of the Russian market. Relying on demand from exclusively private Russian business can enable rapid development of Russian IT companies, but only and (almost) exclusively within national markets. Going beyond these limits, except for specific cases of international cooperation projects etc., is extremely difficult.

Relying on the global financial market is complicated in the early and middle stages of the development of IT companies, and the risks associated with entering the global market while bypassing the domestic one are quite high. In addition, a successful global 
start without a history of success in the national market is unlikely [8].

None of the pure strategies for fostering global champions can be chosen as a target, although separate elements of each strategy can and should be used in the formation of the target scenario.

A possible target strategy that uses the advantages and minimizes the risks of all the pure strategies for fostering global champions is the "sequential transformation" of IT companies.

The first stage is based on cooperation with national industry companies and development institutions and involves scaling an existing IT company up to the level of industry market leaders (including through import substitution in critical spheres), namely, extraction and processing of minerals, energy, the agro-industrial complex, industrial production, the urban economy, education, and transport. Alongside that, focus is also placed on microelectronics and so-called basic IT systems (operating systems and office suites, means of communication, production, and delivery of digital content, etc.).

The second stage is based on interaction with Russian corporations, the REC (Russian Export Center), VEB.RF, and strategic foreign partners (including sovereign wealth funds, mainly those from emerging markets) and consists of introducing the supported Russian IT companies to the global market and scaling them up to the level of industry leaders.

Thus, the first and second stages follow a logic that is close to a combination of the above pure scenarios, scaling that relies on private financing and the state ecosystem.

The third stage involves simultaneously attracting major players to the capital, doing an IPO of the Russian industry IT company, and transforming it into a significant "platform player" in the global market.

Implementation of such a strategy requires one or more coordinating institutions that can use the entire set of competencies for working with technologies and companies, from selection of champions to management of global expansion. Such (an) institution(s) must not be completely state-controlled and can function through consortia of organizations (for example, the IIDF (Internet Initiatives Development Fund), VEB.RF, Sberbank, the RDIF, and major nonfinancial Russian companies from traditional industries).

Financial support for the growth of supported companies to the level of global champions should be based on a number of principles that determine the choice of the type of financial instruments, depending on the company's development stage:

1. The extent to which companies use equity instruments (shares, participation rights) increases as they move to the next stages. The more significant risks at the first stage, provided that a potentially new product/service is offered to the market, limit the likeli- hood that external investors will want to share risks with the founders of the company. It is more profitable for them to provide guaranteed (by the Institute) loans. At the second and third stages of the company's development, the ownership structure is planned to be expanded in order to attract "free" capital.

2. The share of "hybrid" instruments (with the right to participate in the capital under certain conditions) in the equity structure of supported companies is at its maximum in the middle part of the process of fostering champions. The transformation of an IT company into a leader in the domestic market and its active entry into foreign markets will lead to a reduction in investment risks, but they will still be quite high. During this period, investors are likely to be focused on debt financing, but now with the right to convert debt into shares in the company's capital (convertible bonds). In addition, key owners of the IT company will not be inclined to share control while the company has not yet completed the breakthrough to global markets and has not fully realized its value growth potential.

3. The dominant type of debt instruments will change as the company grows. The high risks at the first stage of the development of an IT company mean that lenders will require the maximum possible guarantees of credit recovery. Such requirements can be met through debt project financing, specifically through the Project Finance Factory of VEB.RF. At the second stage, the IT company will be able to attract funds through standard bank loans or issuing corporate bonds on the domestic market. Achieving global leadership at the third stage will require attracting large-scale credit funds, for example, through the international syndicated loan market and issue of Eurobonds.

It is proposed to cover approximately $40 \%$ of financing by expanding the companies' equity, and the rest by means of debt and hybrid financing

Let us emphasize that fostering national champions in the field of ICT can by no means be a goal in and of itself: it only expands the set of measures of stimulating economic growth in general and developing the resource potential of the ICT sector and the demand for its products. Consequently, it also cannot be invariant for different scenarios of Russian economic development, as it is doomed to failure without conditions specific to the target macroeconomic scenario.

The problem is not even just that without such structures Russia will miss out on economic growth. Another issue is that in a world where global BigTech companies dominate the new-industries economy, creating our own companies on a global scale is the only way to avoid a situation in which the effect of our efforts towards ICT development is ultimately mainly absorbed and used by external players. 


\section{ACKNOWLEDGMENTS}

The authors are grateful to A.V. Deshko, a leading expert of the Center for Macroeconomic Analysis and Short-term Forecasting (CMASF), whose materials are used in the article.

\section{FUNDING}

The article was prepared as part of the research project "Development of proposals and models for achieving selfsufficiency of the IT and Internet entrepreneurship Ecosystem, including assessments of the impact of national champion companies," implemented by order and in the interests of the Internet Initiatives Development Fund (Agreement No. 2/6-20-ЕП of May 25, 2020). The research team is headed by D.R. Belousov.

\section{REFERENCES}

1. N. V. Akindinova, M. P. Dombrovski, A. A. Shirov, D. R. Belousov, I. B. Voskoboinikov, and E. T. Gurvich, "Prospects for the recovery of economic growth in Russia (based on the materials of the round table in the framework of the XXI April International Scientific Conference of the National Research University Higher School of Economics)," Vopr. Ekon., No. 7, 5-50 (2020).

2. A. S. Misharin, A. N. Klepach, and D. R. Belousov, Post-Crisis Development of Russia: Modernization, Inno- vation, and Social State. Prospects until 2025 (Ural. Rab., Yekaterinburg, 2011) [in Russian].

3. D. R. Belousov, A. Yu. Apokin, N. A. Ganichev, O. B. Koshovets, E. M. Sabel'nikova, and I. E. Frolov, "Technological development scenarios," in Challenge 2035 (Olimp-Biznes, Moscow, 2016), pp. 180-237 [in Russian].

4. A. Apokin and I. Ipatova, How $R \& D$ Expenditures Influence Total Factor Productivity and Technical Efficiency? (Vyssh. Shk. Ekon., Moscow, 2016).

5. D. R. Belousov and E. A. Penukhina, "On the construction of a qualitative model of the Russian ICT ecosystem," Stud. Russ. Econ. Dev. 29 (3), 295-302 (2018).

6. D. R. Belousov, A. D. Gromov, K. V. Mikhailenko, and E. A. Penukhina, "On the development of Russia's information and communication technologies ecosystem," Stud. Russ. Econ. Dev. 29 (4), 433-441 (2018).

7. The ICT Development Index (IDI): Conceptual Framework and Methodology. https://www.itu.int/en/ ITU-D/Statistics/Pages/publications/mis/methodology.aspx.

8. D. S. Medovnikov, S. D. Rozmirovich, and T. K. Oganesyan, Champion Candidates. Features of Russian FastGrowing Technology Companies, Their Development Strategies, and the State's Ability to Support the Implementation of These Strategies. http://national-champions.ru/upload/iblock/55c/55c998ac9de69249eeda8afb508721b1.pdf.

Translated by A. Ovchinnikova 